\title{
COPD patient's education and self-management teaching: a worthwhile effort?
}

\author{
M. Neri
}

Monaldi Arch Chest Dis 2008; 69: 2, 47-49.

Keywords: COPD, Self-management, Education.

Divisione di Pneumologia Riabilitativa, Fondazione Salvatore Maugeri, I.R.C.C.S., Tradate (Varese), Italy.

Correspondence: M. Neri, Divisione di Pneumologia Riabilitativa, Fondazione Salvatore Maugeri, I.R.C.C.S., Via Roncaccio 16, 21049 Tradate (Varese), Italy; e-mail: margherita.neri@fsm.it

Patient-focused educational interventions are usually designed to support patients in seeking and obtaining appropriate, effective, safe, and efficient health care and to involve patients and families in clinical care and optimal management of chronic diseases [1]. Such interventions can achieve positive effects in many chronic diseases although with the actual results may differ in terms of efficacy and effectiveness $[2,3]$. Usually the patient's education is focused on knowledge and understanding of her/his condition; capability of choosing between therapeutic option; correct drug use and compliance with the physician's prescriptions; impact on health behaviour and health status; use of health services and costs [1]. Many questions still remain open, such as: how is it possible to measure the impact of educational interventions? What are the most relevant outcomes? What is the cost/benefit ratio of an intervention? Is an increased knowledge sufficient to lead to a different behaviour? Is self-management teaching an useful tool for all kind of diseases? [1]

Among respiratory diseases, asthma has become the paradigm of educational necessity and relevance with positive outcomes [3, 4]. For other chronic respiratory diseases, such as COPD, the evidence is still limited, although there is a general agreement about patient's need for education and some positive results have been reported [5, 6]. A Cochrane review [7] reported positive outcomes of educational interventions in COPD patients in respect of health-related quality of life, symptoms, severity of exacerbations; no difference was found regarding courses of oral steroids and/or antibiotics, use of rescue medication, emergency room visits, use of other health care facilities, days absent from work, lung function and exercise capacity.

The hypothetic outcomes of an educational intervention directed to patients with a chronic disease are summarized in table 1 . All the listed outcomes can be implemented in order to improve patients' health knowledge. People need to obtain, process, and understand health information, in or- der to be able to better manage a medical condition or to make good decisions regarding their own health. However, it is not enough that patients have access to and understand health information, it is much more important is to obtain behaviour changes and follow up in positive changes. Patients with low health literacy have poorer health status, higher rates of hospital admission, are less likely to adhere to prescribed treatments and self care plans, experience more drug and treatment errors, and make less use of preventive services [8]. Moreover, a consistent association between better adherence to drug therapy and lower mortality was found in a meta-analysis considering a large amount of studies involving about fifty thousand patients [9].

Evidence suggests that well designed written information (such as book, booklets, and leaflets) can be very useful if added to professional consultation and advice as it can improve health knowledge and recall, especially if information is personalised [3, 4]. In fact, in cases where only information is provided, the outcome is often unsuccessful. However, educational and self help programmes that are actively supported by clinicians can improve patients' knowledge of their condition, quality of life, coping behaviour, adherence, self efficacy, cost effectiveness and health outcomes, has been demonstrated in patients with asthma, diabetes, and hypertension [2, 8, 10]. Providing asthmatic patients with oral and written information through a comprehensive educational programme to has improved their understanding of the disease, resulted in better and more regular use of prescribed drugs, improved symptom management, reduced the number of unscheduled visits and of days spent in hospital, thus reducing the costs of the disease $[3,4]$. The same results were not obtained where only limited information was provided [11].

All of these reasons highlight the need to prepare and test educational tools and as the booklet presented in the paper of Scala and co-workers published in the present issue of Monaldi Archives 
Table 1. - Examples of outcomes of Educational Programs *

\section{Patients' knowledge}

- Knowledge of condition and long term complications

- Self care knowledge

- Knowledge of treatment options and likely outcomes

- Comprehension of information

- Recall of information

\section{Patients' experience}

- Patients' satisfaction

- Doctor-patient communication

- Quality of life

- Psychological wellbeing

- Self efficacy

- Involvement and empowerment of patients

Use of services and costs

- Hospital admission rates

- Emergency admission rates

- Length of hospital stay

- Number of visits to general practitioners

- Cost effectiveness

- Cost to patients

- Days lost from work or school

\section{Health behaviour and health status}

- Health related lifestyles

- Self care activities

- Treatment adherence

- Severity of disease or symptoms

- Physical functioning

- Mental functioning

- Clinical indicators

* modified by Coulter and Ellis, ref [1].

[12] clearly show, it can be a very important and useful method of achieving positive results. Educational intervention directed to a group of COPD patient were successful even though it is usually not considered for this kind of intervention. Combined oral and written information can improve patients' experience and, in some cases, reduce use of health service resources [13]. Moreover the remarkable outcome of this paper is that the positive results were recognisable after one year, a long period for patients to recall information and knowledge.

Beside written material, there are other resources (table 2) that can also be useful in improving knowledge and managing chronic diseases, for example websites, and remote telemonitoring: studies have shown high user satisfaction and beneficial effects on health behaviour, quality of life, use and cost of health services, and, in some cases, physiological outcomes (14), but research in this field is still in the early stages.

There are many options often available to treat a chronic condition and the difference between each option may be unclear or nominal. Treatment choice should therefore be guided by the patient's preferences. The patient should be given all means available so he/she can understand the treatment options and outcome probabilities; the clinician must communicate risk and benefits effectively
Table 2.

\section{Educational Tools for Chronic Patients}

- Printed leaflet, booklets, recorded video or audio

- Self management education

- Self monitoring and self administered treatment prn

- Patient involvement in therapeutic choice

- Encouraging adherence to treatment regimens

- Soliciting patient reporting of adverse drug events

- Self help groups and peer support

- Patient centred telecare

- Computer based and internet health information

- Targeted approaches to tackle low levels of health literacy in disadvantaged groups

- Targeted mass media campaigns

and elicit and respect patients' preferences. This type of partnership approach is usually defined as shared or informed decision making, evidence based patient choice or concordance, guided selfmanagement or co-management [15]. To facilitate shared decision making, patient decision aids have been developed for a wide variety of conditions and treatments, these have been tested in several randomised controlled trials, and have been systematically reviewed to evaluate their effectiveness. The reviews show that such aids improve patients' knowledge and understanding of their condition and of the treatment options and outcome probabilities; they also improve agreement between patients' preferences and subsequent treatment decisions [16, 17]. Self management includes the day to day management of long term conditions such as hypertension, diabetes, asthma and COPD. For example, self monitoring of blood glucose, or Peak Espiratory Flow and respiratory symptoms, or blood pressure, as well as remote telemonitoring, can be both effective and cost effective $[2,3,10]$. Studies so far indicate potential benefits in quality of life, use and cost of health services, and, in some cases, physiological outcomes. Nevertheless, long term outcomes, cost effectiveness, the comparative effectiveness of different self care support strategies, and the relevant components of complex interventions provide the greatest benefit need more adequate evaluation.

In conclusion, educational interventions can improve chronic patients' knowledge and experience, use of health services, health behaviour, and health status. Self-management interventions have been proven as useful tools, also in treating people with chronic respiratory disease: the evidence is greater in asthma but is increasing in COPD. Patients with acute and chronic health problems benefit when they are involved in their care, and evidence suggests that this can lead to better use of resources. Shared decision making and self management are important supportive approaches in chronic diseases management. Health information materials, visual or written, decision aids, self management action plans, are most effective when they supplement or augment, rather than replace, interactions between patients and professionals. 


\section{References}

1. Coulter A, Ellins J. Patient-focused interventions: a review of the evidence. London: Health Foundation, 2006. www.pickereurope.org/Filestore/Publications/QEI_ Review AB.pdf.

2. Deakin $\mathrm{T}$, McShane CE, Cade JE, Williams RDR. Group based training for self-management strategies in people with type 2 diabetes mellitus. Cochrane Database Syst Rev 2005; (2): CD003417.

3. Powell H, Gibson PG. Options for self-management education for adults with asthma. Cochrane Database of Systematic Reviews 2003; Issue 1. Art. No.: CD004107. DOI: 10.1002/14651858.CD004107

4. Toelle BG, Ram FSF. Written individualised management plans for asthma in children and adults. Cochrane Database of Systematic Reviews 2002; Issue 3. Art. No.: CD002171. DOI: 10.1002/14651858.CD002171.pub2

5. Turnock AC, Walters EH, Walters JAE, Wood-Baker R. Action plans for chronic obstructive pulmonary disease. Cochrane Database of Systematic Reviews 2005; Issue 4. Art. No.: CD005074. DOI: 10.1002/14651858. CD005074.pub2

6. Bourbeau J, Collet JP, Schwartzman K, Ducruet T, Nault D, Bradley D and the COPD axis of the Respiratory Health Network of the Fond de la recherche en santé du Québec Education in COPD. Economic Benefits of Self- Management. Chest 2006; 130; 1704-11.

7. Effing TW, Monninkhof EM, van der Valk PDLPM, et $a l$. Self-management education for patients with chronic obstructive pulmonary disease. Cochrane Database of Systematic Reviews 2007; Issue 4. Art. No.: CD002990. DOI: 10.1002/14651858.CD002990.pub2.

8. Eakin EG, Bull SS, Glasgow RE, Mason M. Reaching those most in need: a review of diabetes self-manage- ment interventions in disadvantaged populations. Diabetes Metab Res Rev 2002; 18: 26-35.

9. Simpson SH, Eurich DT, Majumdar SR, et al. A metaanalysis of the association between adherence to drug therapy and mortality. BMJ 2006; 333: 15-18.

10. Takiya LN Peterson AM, Finley RS. Meta-analysis of interventions for medication adherence to antihypertensives. Ann Pharmacother 2004; 38: 1617-1624.

11. Gibson PG, Powell H, Coughlan J, et al. Limited (information only) patient education programs for adults with asthma. Cochrane Database of Systematic Reviews 1998; Issue 1. Art. No.: CD001005.DOI: 10.1002/14651858. CD001005

12. Scala D, Cozzolino S, D'Amato G, et al. Sharing knowledge is the key to success in a patient-physician relationship: how to produce a patient information leaflet on COPD. Monaldi Arch Chest Dis 2008; 69: 50-54.

13. Murray E, Burns J, See TS, Lai R, Nazareth I. Interactive health communication applications for people with chronic disease. Cochrane Database Syst Rev 2005; (4): CD004274.

14. Glueckauf R, Ketterson T. Telehealth interventions for individuals with chronic illness: research review and implications for practice. Professional Psychol Res Pract 2004; 35: 615-27.

15. Warsi A, Wang PS, LaValley MP, Avorn J, Solomon DH. Self-management education programs in chronic disease. Arch Intern Med 2004; 164: 1641-9.

16. O'Connor AM, Stacey D, Entwistle V, et al. Decision aids for people facing health treatment or screening decisions. Cochrane Database Syst Rev 2003; (2): CD001431.

17. Haynes R, Yao X, Degani A, et al. Interventions to enhance medication adherence. Cochrane Database Syst Rev 2005; (4): CD000011.

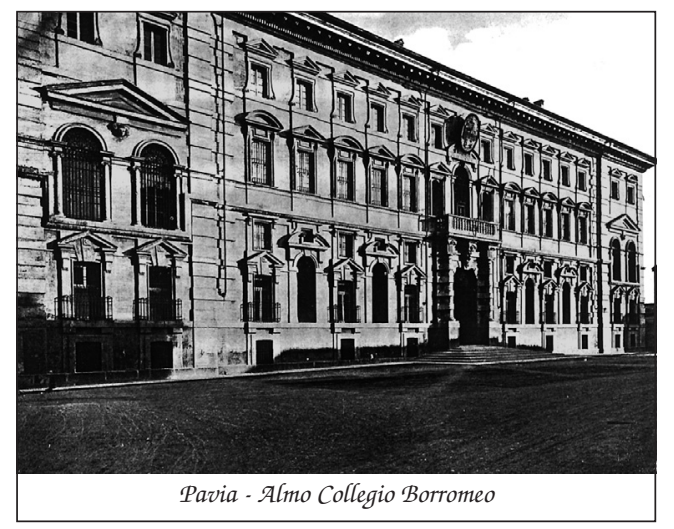

